AperTO - Archivio Istituzionale Open Access dell'Università di Torino

Can the inclusion of black soldier fly (Hermetia illucens) in diet affect the flesh quality/nutritional traits of rainbow trout (Oncorhynchus mykiss) after freezing and cooking?

This is a pre print version of the following article:

Original Citation:

Availability:

This version is available http://hdl.handle.net/2318/1683507

since 2019-12-22T19:14:31Z

Published version:

DOI:10.1080/09637486.2018.1489529

Terms of use:

Open Access

Anyone can freely access the full text of works made available as "Open Access". Works made available under a Creative Commons license can be used according to the terms and conditions of said license. Use of all other works requires consent of the right holder (author or publisher) if not exempted from copyright protection by the applicable law. 


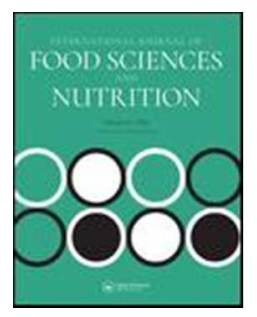

\section{Can the inclusion of black soldier fly (Hermetia illucens) in diet affect the flesh quality/nutritional traits of rainbow trout (Oncorhynchus mykiss) after freezing and cooking?}

\begin{tabular}{|r|l|}
\hline Journal: & International Journal of Food Sciences and Nutrition \\
\hline Manuscript ID & Draft \\
\hline Danuscript Type: & Research Paper \\
\hline Complete List of Authors: & $\begin{array}{l}\text { Secci, Giulia; Universita degli Studi di Firenze Dipartimento di Scienze delle } \\
\text { Produzioni Agroalimentari e dell'Ambiente } \\
\text { Mancini, Simone; University of Pisa, Department of Veterinary Sciences } \\
\text { Iaconisi, Valeria; Universita degli Studi di Firenze Dipartimento di Scienze } \\
\text { delle Produzioni Agroalimentari e dell'Ambiente } \\
\text { gasco, laura; University of Turin,, Department of Agriculture, Forestry and } \\
\text { Food Sciences, } \\
\text { Basto, Ana; University of Porto, dInterdisciplinary Centre of Marine and } \\
\text { Environmental Research } \\
\text { Parisi, Giuliana; Università di Firenze, Biotecnologie Agrarie - Sezione } \\
\text { Scienze Animali }\end{array}$ \\
\hline Keywords: & Feedstuffs, Insect meal, Hermetia illucens, Flesh quality, Malondialdehyde \\
\hline &
\end{tabular}


1 Can the inclusion of black soldier fly (Hermetia illucens) in diet affect the flesh

2 quality/nutritional traits of rainbow trout (Oncorhynchus mykiss) after freezing and

3

4 Giulia Secci $^{\mathrm{a}}$, Simone Mancini ${ }^{\mathrm{b}}$, Valeria Iaconisi ${ }^{\mathrm{a}}$, Laura Gasco $^{\mathrm{c}}$, Ana Basto ${ }^{\mathrm{d}}$, and Giuliana
6

$7 \quad{ }^{\mathrm{a}}$ Department of Agri-Food Production and Environmental Sciences, University of Florence,

$8 \quad$ Via delle Cascine 5, 50144 Firenze, Italy

$9{ }^{b}$ Department of Veterinary Sciences, University of Pisa, Viale delle Piagge 2, 56124 Pisa, 10 Italy

*All correspondence should be addressed to:

Giuliana Parisi - Department of Agri-Food Production and Environmental Sciences, Section of Animal Sciences, University of Florence, via delle Cascine 5, 50144, Florence, Italy

Email: giuliana.parisi@,unifi.it

\begin{abstract}
Physical and chemical parameters of rainbow trout fillets were tested during 120 days of frozen storage and following cooking. The fillets were obtained from rainbow trout fed diets where dietary fishmeal was substituted with Hermetia illucens meal at 0, 25 and 50\%
\end{abstract}


inclusion levels, corresponding to control (C), Hi25, and Hi50 diets. Variations in quality traits of fillets emerged after 30 days of frozen storage, however they remained almost unchanged for the other 90 days. Increasing levels of $H$. illucens did not affect $\mathrm{pH}$, shear stress, colour, and water holding capacity of fillets. Saturated fatty acids were highly present in Hi50 samples, polyunsaturated and some monounsaturated ones were higher in $\mathrm{C}$ than Hi50, whereas Hi25 always assumed intermediate contents in raw and cooked samples. A medium substitution at the $25 \%$ seemed to be the most practical application of insect meal in order to not modify too much the fillets characteristics.

Keywords: Feedstuffs; Insect meal; Hermetia illucens; Flesh quality; Malondialdehyde.

\section{Introduction}

In a world where the global population is expected to grow up to 9 billion by 2050 and the fish stocks are overexploited despite the decline of catches, aquaculture industry has gained an increasingly important role in the fish supply for human consumption (Clarke and Bostock 2017). The expansion of aquaculture industry necessarily implies an increase of aquafeeds production, where high quality fishmeal (FM) has been over the years the preferred protein source, in particular for carnivorous species (Oliva-Teles et al. 2015; Moutinho et al. 2017). However, this resource is limited and cannot be produced in enough quantities to sustain the further development of aquaculture industry. Thus, the decrease of global availability and rising price of this feed ingredient have challenged industry to find more sustainable and costeffective alternatives to FM (Clarke and Bostock 2017; Piccolo et al. 2017).

Recently, the use of insects as alternative protein source to FM has been intensely studied (van Huis et al. 2013; Makkar et al. 2014; Sánchez-Muros et al. 2014; Henry et al. 2015). Insects grow fast, reproduce easily, require much less land, energy, and water than plant and 
51 other conventional animal protein feedstuffs. Furthermore, some insects may be raised on

52 low-value products and their waste can be used as organic fertilizer, they have few animal welfare issues, and low hazard of transferring zoonotic infections (van Huis et al. 2013; Sánchez-Muros et al. 2014; Henry et al. 2015). Although insect production industry is recent, it has high potential and is developing fast (Rumpold and Schlüter 2013; van Huis et al. 2013). Among different species, Hermetia illucens larvae and prepupae have been widely studied. They contain approximately $40-44 \%$ of protein (on dry matter basis, DM) with an amino acid profile particularly rich in lysine (6-8\% of the protein), and up to $40 \%$ (on DM) of fat. H. illucens larvae are rich in minerals such as calcium (5-8\% DM) and phosphorous (0.61.5\% DM) (St-Hilaire et al. 2007; van Huis et al. 2013; Oliva-Teles et al. 2015) and earlier studies showed that $H$. illucens can reduce harmful bacteria in the microflora of manure, acting as natural antibiotic (Makkar et al. 2014; Henry et al. 2015).

Rainbow trout (Oncorhynchus mykiss) is one of the leading cultured freshwater fish species in Europe and therefore has a huge economic importance in the European aquaculture (Clarke and Bostock 2017). Its role in human nutrition is mainly linked to its high biological value protein and polyunsaturated fatty acid (PUFA) content, as for many fish species. However, fillets composition may deeply vary due to both infra vitam and post mortem factors. Diets and storage are two of those. For this reason, the present study aimed to primarily evaluate the effect of dietary replacement of FM by H. illucens meal on quality traits of rainbow trout fillets, and secondarily, in order to understand physical and chemical modification occurred in fillets as a commercial product, the effect of frozen storage up to three months along with the effect of cooking (i.e. ready to eat) was also studied.

\section{Materials and methods}

\subsection{Experimental diets, fish feeding and sampling}


76 Three experimental diets were formulated to be isoproteic (crude protein: $45 \% \mathrm{DM}$ ), 77 isolipidic (ether extract: 15\% DM) and isoenergetic (22 $\mathrm{MJ} \mathrm{kg}^{-1}$ gross energy). Control diet 78 (C) was formulated including only fishmeal as protein source while the other two

79

80 experimental diets presented a substitution of fishmeal with H. illucens larvae meal (Hi; Hermetia Deutschland GmbH \& Co., Baruth/Mark, Germany) at the substitution percentages of 25\% (Hi25) and 50\% (Hi50). Three-hundred and sixty rainbow trout (O. mykiss) were housed in twelve tanks (four thanks per diet). Farming condition and chemical composition of the experimental diets were reported in previous publications (Borgogno et al. 2017; Renna et al. 2017). At the end of the feeding trial, all fish were individually weighed and 4 fish from each tank (16 fish per diet, for a total of 48 animal) were euthanized by an overdose of anaesthesia (Tricaine methane-sulfonate, MS-222; $60 \mathrm{mg} \mathrm{L}{ }^{-1}$; PHARMAQ Ltd., United Kingdom). The day after slaughtering, the fish were transported, in refrigerated boxes, to the Department of Agri-Food Production and Environmental Sciences (DISPAA), University of Florence (Italy).

In order to investigate the effect of frozen storage, the fish were kept at $-10{ }^{\circ} \mathrm{C}$ and analysed fresh (1 day after slaughtering, T1) and after 30, 90 and 120 days of frozen storage (T30, T90 and T120). During this period, all fish were maintained in obscurity in polystyrene boxes. At each different storage time, the fish (12 in total, i.e. 4 for each treatment per time) were dissected and filleted. Right fillets were analysed as raw, while left fillets were analysed as cooked. Left fillets were weighed, vacuum packed in plastic bags and boiled (at $98-100{ }^{\circ} \mathrm{C}$ ) for 5 minutes, until the core temperature arrived at $58{ }^{\circ} \mathrm{C}$; then, the bags containing the samples were removed from the water and cooled at room temperature and the fillets, removed from the bags, were weighed again in order to calculate the cooking loss.

\subsection{Physical analyses}


101 Muscle $\mathrm{pH}$ was measured in triplicate on the cranial, medial and caudal positions of the

102 epaxial region of the raw fillets. The mean value for each fish was utilized in data analysis. A 103 Mettler Toledo DevenGo SG2 ${ }^{\mathrm{TM}} \mathrm{pH}-$ meter (Novate Milanese, Milano, Italy) equipped with an 104 Inlab puncture electrode (Mettler-Toldedo, Ltd) was utilized.

105 For texture measurements, a ZwickRoell ${ }^{\circledR} 109$ texturometer (Zwick Roell, Ulm, Germany), 106 equipped with a $1 \mathrm{kN}$ load cell and supplied by the Text Expert II ${ }^{\circledR}$ software was utilized. The 107 Warner-Bratzler shear test was performed on a muscle sample $(3 \times 3 \mathrm{~cm})$ obtained from the 108 cranial part of the epaxial region of the fillet (one measurement for each fillet). A straight 109 blade (width of $7 \mathrm{~cm}$ ), perpendicular to muscle fibre direction, was utilized at a crosshead 110 speed of $30 \mathrm{~mm} \mathrm{~min}^{-1}$ to $50 \%$ of total deformation as described in Iaconisi et al. (2018). 111 Maximum shear force was determined in both raw and cooked fillets.

112 Colour measurements were performed in both raw and cooked fillets on both the dorsal and 113 ventral regions, by a Spectro-color ${ }^{\circledR} 116$ colorimeter (Bell Technology Ltd., Auckland, New 114 Zealand) equipped with Spectral qc 3.6 software. Colour was expressed as lightness $\left(L^{*}\right)$, 115 redness index $\left(a^{*}\right)$ and yellowness index $\left(b^{*}\right)$ according to the CIELab system (CIE 1976). 116 From $L^{*}, a^{*}$ and $b^{*}$ values, the software automatically calculates Chroma (C*, saturation) and 117 Hue $\left(\mathrm{H}^{*}\right.$, perception) indexes.

118 Water Holding Capacity (WHC), performed only in the raw fillets, was determined according 119 to Iaconisi et al. (2018). WHC was calculated as the percentage of water loss after 120 centrifugation $(5 \mathrm{~min}$ at $210 \times \mathrm{g}$ ) in relation to the water content of the sample. This last value 121 was obtained gravimetrically on $2 \mathrm{~g}$ of sample by weighing samples before and after 24 hours 122 at $105^{\circ} \mathrm{C}$. Two measurements for each sample were performed.

\subsection{Chemical analyses}

125 2.3.1. Fatty acid profile 
126 Total lipid fraction was extracted from both raw and cooked fillets (Folch et al. 1957) and

127 subsequently gravimetrically quantified. The extracted lipids were utilized for the analysis of 128 fatty acid (FA) profile.

129 The FA composition was determined by gas chromatography (GC) using a Varian GC 430 130 gas chromatograph (Agilent, Palo Alto, CA, USA), equipped with a flame ionization detector 131 (FID); a Supelco Omegawax ${ }^{\mathrm{TM}} 320$ capillary column $(30 \mathrm{~m} \times 0.32 \mathrm{~mm}$ i.d., $0.25 \mu \mathrm{m}$ film and 132 polyethylene glycol bonded phase; Supelco, Bellefonte, PA, USA) was utilized. The oven 133 temperature was held at $100{ }^{\circ} \mathrm{C}$ for 2 minutes, increased to $160{ }^{\circ} \mathrm{C}$ over 4 minutes at the rate 134 of $12{ }^{\circ} \mathrm{C} \mathrm{min}^{-1}$, and then increased to $220^{\circ} \mathrm{C}$ over 14 min at the rate of $3{ }^{\circ} \mathrm{C} \mathrm{min}^{-1}$ and kept at $135220{ }^{\circ} \mathrm{C}$ for $25 \mathrm{~min} .$. The injector and the detector temperatures were set at $220{ }^{\circ} \mathrm{C}$ and $300{ }^{\circ} \mathrm{C}$, 136 respectively. A quantity of $1 \mu \mathrm{L}$ of sample in hexane was injected into the column with the 137 carrier gas (helium) kept at a constant flow of $1.5 \mathrm{~mL} \mathrm{~min}^{-1}$. The split ratio was 1:20. 138 Chromatograms were recorded with the Galaxie Chromatography Data System 1.9.302.952 139 computing integrator software (Agilent). FAs were identified by comparing the FAME 140 retention time with the standard Supelco 37 component FAME mix (Supelco, Bellefonte, PA, 141 USA). Individual FAs were quantified using tricosanoic acid (C23:0) (Supelco, Bellefonte, 142 PA, USA) as internal standard and expressed as a percentage of total FAME.

143 From the FA profile, fat quality indexes as atherogenicity index (AI) and thrombogenicity 144 index (TI) (Ulbricht and Southgate 1991) and hypocholesterolemic/hypercholesterolemic FA 145 ratio $(\mathrm{HH})$ (Santos-Silva et al. 2002) were calculated as follows:

$$
\begin{aligned}
& \mathrm{AI}=[\mathrm{C} 12: 0+(\mathrm{C} 14: 0 \times 4)+\mathrm{C} 16: 0] /(\mathrm{PUFA} \omega 3+\mathrm{PUFA} \omega 6+\mathrm{MUFA})
\end{aligned}
$$

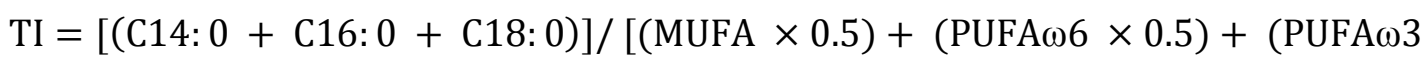

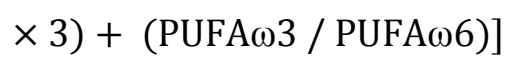

$$
\begin{aligned}
& \mathrm{HH}=(\mathrm{C} 18: 1 \omega 9+\mathrm{C} 18: 2 \omega 6+\mathrm{C} 20: 4 \omega 6+\mathrm{C} 18: 3 \omega 3+\mathrm{C} 20: 5 \omega 3+\mathrm{C} 22: 5 \omega 3 \\
& +\mathrm{C} 22: 6 \omega 3) /(\mathrm{C} 14: 0+\mathrm{C} 16: 0)
\end{aligned}
$$




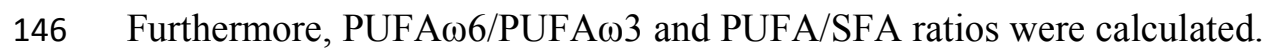

147

148

149

150

151

152

153

154

155

156

157

158

159

160

161

162

163

164

165

166

167

168

169

170

\subsubsection{Lipid oxidation products}

The content of conjugated dienes (CD) was measured by a colorimetric method (Srinivasan et al. 1996), using hexane as solvent. CD were quantified at $233 \mathrm{~nm}$ (50 Scan spectrophotometer equipped with Cary Win UV software, Varian, Palo Alto, CA, USA), using a molar extinction coefficient of $29000 \mathrm{~L} \mathrm{~mol}^{-1} \mathrm{~cm}^{-1}$. Results were expressed as mmol hydroperoxides $\mathrm{kg}^{-1}$ sample. The 2-thiobarbituric acid-reactive substances (TBARS) were measured by a colorimetric method (Salih et al. 1987). TBARS were extracted in $10 \mathrm{~mL}$ of trichloroacetic acid (TCA, $50 \mathrm{~g} \mathrm{~L}^{-1}$ ). Five $\mathrm{mL}$ of the filtered extract was then added with $5 \mathrm{~mL}$ of thiobarbituric acid (TBA, $0.02 \mathrm{~mol} \mathrm{~L} \mathrm{~L}^{-1}$ ). After 40 minutes of incubation at $97{ }^{\circ} \mathrm{C}$, the malondialdehyde equivalents (MDA-eq) were determined spectrophotometrically at $532 \mathrm{~nm}$. A calibration curve obtained by 1,1,3,3-tetraethoxypropane (TEP) at a concentration ranging from 0.8 to $8 \mu \mathrm{mol} \mathrm{L}{ }^{-1}$ was utilized in order to calculate the mg MDA-eq. for kg sample.

\subsection{Statistical analyses}

Data obtained on raw fillets $(\mathrm{pH}, \mathrm{WHC}$, cooking loss, maximum shear force, colour, FA profile and lipid oxidation products) and on cooked samples (maximum shear force, colour and FA profile) were analysed separately. A two-way ANOVA analysis was applied with the diet (D; C, Hi25 and Hi50) and the storage time (T; T1, T30, T60 and T120) as fixed factors. Lipid oxidation products (CD, and TBARS) on raw samples were analysed only at $\mathrm{T} 1$ and T120.

Interaction $\mathrm{D} \times \mathrm{T}$ was assessed and the significance level was set at 5\% (statistically significant for $P<0.05$ ), and the differences were assessed using Tukey's test. Variability was expressed as Root Mean Square Error (RMSE). 
171 Moreover, data of raw and cooked samples were also separately analysed through a principal

172 component analysis (PCA). Both raw and cooked sample data were mean centered and scaled 173 to a unit standard deviation before PCA analyses.

174 Statistical analyses were performed with R free statistical software.

175

176

177

178

179

180

181

182

183

184

185

186

187

188

189

190

191

192

193

194

195

\section{Results and discussions}

\subsection{Physical analyses}

Table 1 shows the results obtained from physical analyses $(\mathrm{pH}$, shear stress, colour, WHC and cooking loss) of raw and cooked fillets. Regarding data of raw fillets, none of the considered parameters has been affected by the substitution of fishmeal with H. illucens larvae meal, thus confirming previous findings (Renna et al. 2017). Indeed, both $\mathrm{pH}$ value, $a^{*}$ and $b^{*}$ colour values were in line to those proposed during the evaluation of the suitability of a partially defatted H. illucens meal as ingredient for rainbow trout diet (Renna et al. 2017).

On the contrary, storage time had a significant effect on $\mathrm{pH}$ and texture, by significantly increasing the first and decreasing the second parameter. Specifically, $\mathrm{pH}$ remained unaltered along the first 30 storage days, and then slightly increased by raising its highest value at T120. Texture instead, expressed as shear force, widely decreased from $\mathrm{T} 1$ and $\mathrm{T} 30$, remained stable during the following 60 days, until T90, and finally it raised an intermediate value, among the other times, at the end of the storage period. Concerning colour, $L^{*}, b^{*}$, and $\mathrm{C}^{*}$ values of both the considered regions resulted significantly increased by increasing the storage time. Since years, authors have been investigating the effect of storage on colour parameters studying the combination temperature-duration. An increase in $L^{*}, a^{*}$ and $b^{*}$ with long storage time was found in pigmented rainbow trout vacuum packed fillets (No and Storebakken 1991) and in Atlantic salmon (Salmo salar) (Regost et al. 2004), thus being in line with the data obtained in the present study. 
196 However, it is possible to observe that colour modification differently occurred in dorsal and 197 ventral regions. Indeed, $L^{*}, b^{*}$, and $C^{*}$ values of the dorsal region tended to remain stable 198 during the first 30 days of storage, then gradually increased $(P<0.05)$ during the storage till 199 assuming their highest values at T120. Instead, $L^{*}, b^{*}$, and $\mathrm{C}^{*}$ of the ventral region already 200 changed $(P<0.05)$ between $\mathrm{T} 1$ and T30 by raising their maximum values which were no 201 more modified during the remaining storage days. Other authors have previously noticed that 202 different part of the fish fillet might present different colour values. No and Storebakken 203 (1991) for example, underlined that $L^{*}, a^{*}$, and $b^{*}$ significantly differed among neck, back, 204 and tail positions along rainbow trout fillets. Also other authors found that epaxial and 205 hypaxial regions of trout flesh presented different $b^{*}$ values (Iaconisi et al. 2017). Since 206 colour is correlated with proximate composition, especially with lipid content, and 207 considering the high variability in lipid distribution along fish fillets, we might attribute the 208 different pattern in colour maintenance during storage to a different stability of chemical 209 components of flesh (Martelli et al. 2014).

210 Water holding capacity of raw fillets resulted unaffected by both diet and storage, assuming a 211 mean value around 85\%. Diet did not affect cooking loss as well, while a light trend of 212 increase was shown during the storage trial, however T1 and T120 not significantly differed.

213 As reported for raw samples, also quantifications of shear stress and colour on cooked fillets 214 were not significantly modified by the diet (Table 1). Colour is widely reported to play an 215 important role in consumers' acceptance of cooked fish (Gai et al. 2016), hence the absence of 216 a significant effect of diet on this quality parameter should be considered as positive when 217 evaluating $H$. illucens meal inclusion as substitute for fishmeal in rainbow trout feed.

218 As found for raw fillets, storage time had a significant effect on physical parameters. Shear 219 stress increased up to T120, when its value was $+37 \%$ of T1. Finally, colour evaluation of 220 cooked fillets revealed that $\mathrm{a}^{*}$ values of both dorsal and ventral regions were modified by 
221 storage time but following an opposite pattern. Specifically, dorsal region presented an

222 increase $(P<0.05)$ in $\mathrm{a}^{*}$ value during the first 30 days and no other modifications were noted

223 till the end of the trial. Contrarily, a* values of ventral portion decreased from T1 to T120,

224 however this last sampling point was not significantly different from the first one.

225

226

3.2. Chemical analyses

227 3.2.1. Fatty acid profile

228 Total lipid and fatty acid contents were unaffected by the diet. Nevertheless, fatty acid profile

229 of raw fillets was strongly affected by H. illucens larvae meal inclusion level in the diet, as

230 shown in Table 2. An overall increase of saturated fatty acid (SFA) was observed while

231 increasing the percentage of fish meal replacement with $H$. illucens meal. As a consequence,

232 the highest SFA value was found in fillets from Hi50, mostly by C12:0 and C14:0 wide

233 increase; Hi25 assumed intermediate values, whereas C group presented the lowest SFA

234 value. Among this lipid category, C16:0 and C18:0 were unaltered by the diet. The opposite

235 pattern was shown by monounsaturated fatty acids (MUFA) and polyunsaturated fatty acids

236 (PUFAw3 and total PUFA) groups. The contents of all the MUFA were significantly lower in

237 Hi50 than in $\mathrm{C}$, with the exception of $\mathrm{C} 16: 1 \omega 7$. PUFA $\omega 3$ gradually decreased with the

238 inclusion of $H$. illucens larvae meal in aquafeed. The highest and lowest PUFA $\omega 3$ contents

239 were found in fillets from $\mathrm{C}$ and Hi50 diet, respectively, whilst Hi25 once again assumed

240 intermediate values. A dramatic half reduction of eicosapentaenoic acid (EPA, C20:5

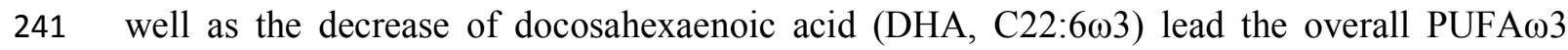

242 reduction. On the contrary, PUFAw6 fraction was constant between fillets from trout fed C

243 and Hi50 diet. Due to this deeply modification, PUFA/SFA ratio was found below 1 only in

244 Hi50 group, whereas a ratio of 1.71 and 1.12 was calculated for C and Hi25, respectively.

245 Fish fatty acid profile usually reflects the one of the administered diet. In this sense, the 
246 progressive decrease of PUFA 13 , together with the increase of SFA, seems to be attributable

247 to two factors, both related to the presence of H. illucens larvae meal in feed. First of all, it is

248 important to consider that H. illucens meal utilized in the present trial was partially defatted,

249 and it had around $17 \%$ of fat content. Hence, in order to maintain the diet isoenergetic, the

250 increased presence of insect larvae meal implied the contemporary reduction of fish oil, the

251 main source of PUFAw3 in aquafeed (Borgogno et al. 2017; Renna et al. 2017). Secondarily,

252 H. illucens fat is characterized by high level of SFA, which might amount at $71.80 \%$ and

$25354.59 \%$ of total fatty acid in prepupae and larvae meal, respectively, irrespective the growing 254 substrates (Borgogno et al. 2017, Renna et al. 2017). A recent study has suggested that $H$. 255 illucens is able to both synthesize C12:0 from nutrients present in the substrate, such as 256 carbohydrates (starch and sugars), and metabolize to C12:0 a large proportion of fatty acid 257 (Oonincx et al. 2015) as form of biological storage. However, in light of the fact that a 258 substitution of $50 \%$ of fish meal with $H$. illucens meal deeply reduced PUFA $\omega 3$ fraction, a 259 defatted phase should be considered while producing this insect meal for aquafeeds.

260 Storage time seemed to have a little effect on fatty acid profile of raw fillets, thus confirming 261 the suitability of frozen storage for lipid preservation. SFA fraction, especially C12:0 and 262 C14:0, slight but significantly increased during the first 30 days of storage, and they remained 263 unchanged until T120. Thirty days of frozen storage seemed to be critical for C22:5 264 was significantly lower at T30, T90 and T120 than at T1. No other significant variation 265 emerged from the statistical analysis.

266 The fatty acid profile of the rainbow trout cooked fillets (Table 3) was very similar to the 267 profile of the raw ones, in terms of the percentages of each fatty acid and of trends. All the 268 reported fatty acids were affected by the diet, except $\mathrm{C} 18: 0, \mathrm{C} 16: 1 \omega 7$, and $\mathrm{C} 18: 2 \omega 6$. As found 269 in raw fillets, SFA significantly increased in cooked fillets with the increasing of H. illucens 270 meal in diet, whereas all the other fatty acid fractions decreased $(P<0.05)$. Due to these 
271 modifications, all the calculated nutritional indexes were negatively affected by rising insect

272 meal level in diet. The worsening of lipid quality with insect meal introduction in aquafeed 273 was also confirmed by the gradual but significant decrease of $\omega 3 / \omega 6$, PUFA/SFA, and HH 274 ratios as well as by the $\mathrm{AI}$ and TI values increase in fillets from trout fed Hi50. However, the 275 only recommendation about PUFAs intake in relation with their role in human health, is the 276 amount of EPA + DHA per day, suggested in $500 \mathrm{mg}$ (Kris-Etherton et al. 2009). While 277 looking at present results, EPA and DHA reduction in rainbow trout cooked fillets, as a 278 consequence of growing levels of $H$. illucens in fish diet, implied that consumers should 279 increase the number of portions (around $100 \mathrm{~g}$ as suggested by US Food and Drug 280 Administration) consumed every week. Specifically, in order to introduce the suggested $3.5 \mathrm{~g}$ 281 of EPA + DHA per week, people should eat around $196 \mathrm{~g}$ (equivalent to 2 scarce portions), $282254 \mathrm{~g}$ (equivalent to 2.5 portions), and $311 \mathrm{~g}$ (equivalent to 3 portions) of trout fed with C, 283 Hi25, and Hi50 diets, respectively.

284 The effect of storage time on fatty acid profile of cooked fillets was less extended than that of 285 the diet. Indeed, only few fatty acids resulted affected by storage. Significant increases of $286 \mathrm{C} 12: 0$ and $\mathrm{C} 14: 0$ lead the overall increase $(P<0.05)$ in total SFA fraction during the storage.

287 On the contrary, a decrease of PUFAw3 was shown at T30 $(P<0.01)$, with a single decrease 288 of around $8 \%$ and $12 \%$ of content for $\mathrm{C} 22: 5 \omega 3$ and $\mathrm{C} 22: 6 \omega 3$, respectively. It has to be 289 underlined that all of these changes occurred during the first 30 days of storage, hence T1 data 290 resulted significantly different from T30, T90, and T120, with no further modification among 291 these last three sampling times.

292

293

\subsubsection{Lipid oxidation products}

294 Lipid oxidation was evaluated only in raw fillets by determining both primary (conjugate 295 dienes, CD) and secondary (TBARS, as MDA-eq) oxidation products. No statistical 
296 significance for the main factors and their interaction was found for CD quantification.

297 Instead, interaction of treatments $\mathrm{D} \times \mathrm{T}$ was found significant by the statistical analysis for

298 MDA-eq quantification (Figure 1). Figure 1 shows that fillets from $\mathrm{C}$ dietary group were the 299 most susceptible to be oxidized, indeed, they contained the highest level of MDA-eq at T120, 300 equal to $2.60 \mathrm{mg}$ MDA-eq $\mathrm{kg}^{-1}$. This fact might be due to the highest PUFAs content in $\mathrm{C}$ 301 fillets, which is the main lipid fraction to be damaged by oxidative phenomena, as confirmed 302 by fatty acid profile patterns during storage. However, a recent paper has observed that dietary defatted $H$. illucens larvae meal improved the antioxidant status of Jian carp (Cyprinus carpio var. Jian) by showing a high catalase activity (CAT) in animal serum (Li et al. 2017).

305

306

\subsection{Principal component analysis}

Principal component analyses on raw and cooked fillets are reported as biplot (score plot and loading plot) in Figures 2 and 3, respectively. Samples were grouped for type of diet in both plots, revealing that the PC 1 could be related to the substitution of fishmeal with Hi meal. Indeed, more fishmeal was replaced with Hi meal more the diet samples were plotted distant from the $\mathrm{C}$ diet samples. As revealed from fatty acid analysis, fillets were grouped mostly in relation to fatty acid profile; SFA were highly present in Hi50 samples, as well as PUFA and in part MUFA were higher in C samples than in Hi25 and Hi50 ones.

PC 2 was not representative for the storage time, as samples were mixed between time of analysis on the $\mathrm{y}$ axis, even if a trend to plot the $\mathrm{T} 1$ in the upper squares of the plots were revealed in both raw and cooked PCAs. This finding might be expected as storage time 
321 showed to significantly affect the parameters investigated only in few cases, with major

322 differences between $\mathrm{T} 1$ fillet characteristics and the characteristics of fillets analysed at the

323 other times. Results of cooked samples followed the trends of the raw ones. The same

324 distribution of the loadings could be highlighted in both the plots, with quite the same position

325 of the plotted analyses (i.e. for the same type of determination the eigenvectors of the raw and 326 the cooked PCA were comparable).

327

328

329

330

331

332

333

334

335

336

337

338

339

340

341

\section{Conclusion}

Substitution of fishmeal with Hermetia illucens meal in rainbow trout diet mainly induced modifications in fatty acid composition of raw and cooked fillets. Variations in quality/nutritional traits of fillets emerged after 30 days of frozen storage, with minor modification during the rest of the storage period. The worsening in nutritional characteristics of cooked fillets due to insect meal inclusion increased the fillets portion needed to carry the weekly suggested intake of EPA and DHA. A medium substitution at the $25 \%$ of fishmeal with this new ingredient for aquafeeds seemed to be the most practical application in order to not substantially modify the fillets characteristics.

\section{Funding}

The research was funded by the University of Florence, Ateneo Research Project (2014) and by the University of Turin, ex-60\% grant (2014). 


\section{References}

343 Borgogno M, Dinnella C, Iaconisi V, Fusi R, Scarpaleggia C, Schiavone A, Monteleone E, Gasco L, Parisi G. 2017. Inclusion of Hermetia illucens larvae meal on rainbow trout (Oncorhynchus mykiss) feed: effect on sensory profile according to static and dynamic evaluations. J. Sci. Food Agric. 97:3402-3411.

Clarke R, Bostock J. 2017. Regional review on status and trends in aquaculture development in Europe - 2015. Rome, Italy.

Commission Internationale de l'Eclairage - CIE. 1976.Official recommendations on uniform colour spaces, colour differences equations and metric colour terms. Paris, France.

Folch J, Lees M, Sloane-Stanley GH. 1957. A simple method for the isolation and purification of total lipides from animal tissues. J. Biol. Chem. 226:497-509.

Gai F, Peiretti PG, Brugiapaglia A, Gasco L. 2016. Effects of dietary protein source and feeding regime on growth performance, nutrient digestibility, fatty acids, and quality characteristics of rainbow trout, Oncorhynchus mykiss, fillets. J. World Aquac. Soc. $47: 496-507$.

Henry M, Gasco L, Piccolo G, Fountoulaki E. 2015. Review on the use of insects in the diet of farmed fish: Past and future. Anim. Feed Sci. Technol. 203:1-22.

Iaconisi V, Bonelli A, Pupino R, Gai F, Parisi G. 2018. Mealworm as dietary protein source for rainbow trout: Body and fillet quality traits. Aquaculture. 484:197-204.

Iaconisi V, Marono S, Parisi G, Gasco L, Genovese L, Maricchiolo G, Bovera F, Piccolo G. 2017. Dietary inclusion of Tenebrio molitor larvae meal: Effects on growth performance and final quality treats of blackspot sea bream (Pagellus bogaraveo). Aquaculture. 476:49-58.

Kris-Etherton PM, Grieger JA, Etherton TD. 2009. Dietary reference intakes for DHA and EPA. Prostaglandins, Leukot. Essent. Fat. Acids. 81:99-104. 
367 Li S, Ji H, Zhang B, Zhou J, Yu H. 2017. Defatted black soldier fly (Hermetia illucens) larvae 368 meal in diets for juvenile Jian carp (Cyprinus carpio var. Jian): Growth performance, antioxidant enzyme activities, digestive enzyme activities, intestine and hepatopancreas histological structure. Aquaculture. 477:62-70.

Makkar HPS, Tran G, Heuzé V, Ankers P. 2014. State-of-the-art on use of insects as animal feed. Anim. Feed Sci. Technol. 197:1-33.

Martelli R, Franci O, Lupi P, Faccenda F, Parisi G. 2014. Physico-chemical traits of raw and cooked fillets of rainbow trout (Oncorhynchus mykiss) from different strains and farms. Ital. J. Anim. Sci. 13:3417.

Moutinho S, Martínez-Llorens S, Tomás-Vidal A, Jover-Cerdá M, Oliva-Teles A, Peres H. 2017. Meat and bone meal as partial replacement for fish meal in diets for gilthead seabream (Sparus aurata) juveniles: Growth, feed efficiency, amino acid utilization, and economic efficiency. Aquaculture. 468:271-277.

Ngo D-H, Kim S-K. 2014. Antioxidant effects of chitin, chitosan, and their derivatives. Academic Press. Advances in food and nutrition research; p. 15-31.

No HK, Storebakken T. 1991. Color stability of rainbow trout fillets during frozen storage. J. Food Sci. 56:969-972.

Oliva-Teles A, Enes P, Peres H. 2015. Replacing fishmeal and fish oil in industrial aquafeeds for carnivorous fish. Oxford (UK): Woodhead Publishing. Feed and Feeding Practices in Aquaculture; p. 203-233.

Oonincx DGAB, van Broekhoven S, van Huis A, van Loon JJA. 2015. Feed conversion, survival and development, and composition of four insect species on diets composed of food by-products. PLoS One. 10:e144601.

Piccolo G, Iaconisi V, Marono S, Gasco L, Loponte R, Nizza S, Bovera F, Parisi G. 2017. Effect of Tenebrio molitor larvae meal on growth performance, in vivo nutrients 
392

393

394

395

396

397

398

399

400

401

402

403

404

405

406

407

408

409

410

411

412

413

414

415

416

digestibility, somatic and marketable indexes of gilthead sea bream (Sparus aurata). Anim. Feed Sci. Technol. 226:12-20.

Regost C, Jakobsen JV, Rørå AMB. Flesh quality of raw and smoked fillets of Atlantic salmon as influenced by dietary oil sources and frozen storage. Food Res. Int. 37:259271.

Renna M, Schiavone A, Gai F, Dabbou S, Lussiana C, Malfatto V, Prearo M, Capucchio MT, Biasato I, Biasibetti E, De Marco M, Brugiapaglia A, Zoccarato I, Gasco L. 2017. Evaluation of the suitability of a partially defatted black soldier fly (Hermetia illucens L.) larvae meal as ingredient for rainbow trout (Oncorhynchus mykiss Walbaum) diets. J. Anim. Sci. Biotechnol. 8:57.

Rumpold BA, Schlüter OK. 2013. Potential and challenges of insects as an innovative source for food and feed production. Innov. Food Sci. Emerg. Technol. 17:1-11.

Salih AM, Smith DM, Price JF, Dawson LE. 1987. Modified extraction 2-thiobarbituric acid method for measuring lipid oxidation in poultry. Poult. Sci. 66:1483-1488.

Sánchez-Muros MJ, Barroso FG, Manzano-Agugliaro F. 2014. Insect meal as renewable source of food for animal feeding: A review. J. Clean. Prod. 65:16-27.

Santos-Silva J, Bessa RJ., Santos-Silva F. 2002. Effect of genotype, feeding system and slaughter weight on the quality of light lambs: II. Fatty acid composition of meat. Livest. Prod. Sci. 77:187-194.

Srinivasan S, Xiong YL, Decker EA. 1996. Inhibition of protein and lipid oxidation in beef heart surimi-like material by antioxidants and combinations of $\mathrm{pH}, \mathrm{NaCl}$, and buffer type in the washing media. J. Agric. Food Chem. 44:119-125.

St-Hilaire S, Cranfill K, McGuire MA, Mosley EE, Tomberlin JK, Newton L, Sealey W, Sheppard C, Irving S. 2007. Fish offal recycling by the black soldier fly produces a foodstuff high in omega-3 fatty acids. J. World Aquac. Soc. 38:309-313. 
417 Ulbricht TL, Southgate DA. 1991. Coronary heart disease: seven dietary factors. Lancet. $418 \quad 338: 985-992$.

419 van Huis A, Van Itterbeeck J, Klunder H, Mertens E, Halloran A, Muir G, Vantomme P. 420 2013. Edible insects Future prospects for food and feed security. Food and Agriculture 421 Organization of the United Nations - FAO. Rome, Italy. 
1 Table 1. Physical analyses $(\mathrm{pH}$, shear stress, colour, water holding capacity, and cooking 2 loss) of raw and cooked fillets from rainbow trout fed three experimental diets: Control (C) 3 with fish meal as the main protein source, Hi25, and Hi50 with the $25 \%$ and $50 \%$ of fish meal 4 substitution by Hermetia illucens, respectively. Fillets from the three groups where stored 120 5 days at $-10^{\circ} \mathrm{C}$.

\begin{tabular}{|c|c|c|c|c|c|c|c|c|c|c|c|}
\hline & \multicolumn{3}{|c|}{ Diet (D) } & \multicolumn{4}{|c|}{ Time $(\mathrm{T})$} & \multicolumn{2}{|c|}{$P$-value } & \multirow{2}{*}{ RMSE } \\
\hline & & $\mathrm{C}$ & Hi25 & Hi50 & T1 & T30 & T90 & T120 & $\bar{D}$ & $\mathrm{~T}$ & \\
\hline \multicolumn{12}{|l|}{ Raw fillet } \\
\hline $\mathrm{pH}$ & & 6.41 & 6.43 & 6.42 & $6.37^{\mathrm{z}}$ & $6.40^{\mathrm{yz}}$ & $6.44^{x y}$ & $6.47^{\mathrm{x}}$ & 0.521 & $<0.001$ & 0.050 \\
\hline Shear stress, N & & 12.79 & 14.59 & 14.68 & $19.42^{x}$ & $10.34^{\mathrm{z}}$ & $11.12^{\mathrm{z}}$ & $15.21^{\mathrm{y}}$ & 0.060 & $<0.001$ & 2.445 \\
\hline \multicolumn{12}{|l|}{ Colour } \\
\hline \multirow[t]{5}{*}{ Dorsal } & $L^{*}$ & 50.38 & 50.63 & 50.33 & $45.95^{z}$ & $47.36^{\mathrm{z}}$ & $51.86^{\mathrm{y}}$ & $56.61^{x}$ & 0.946 & $<0.001$ & 2.661 \\
\hline & $a^{*}$ & -0.21 & -0.35 & 0.14 & -0.14 & -0.13 & 0.07 & -0.36 & 0.435 & 0.820 & 1.091 \\
\hline & $b^{*}$ & 5.59 & 5.40 & 6.23 & $3.67^{\mathrm{y}}$ & $4.64^{\mathrm{y}}$ & $7.38^{x}$ & $7.27^{\mathrm{x}}$ & 0.188 & $<0.001$ & 1.315 \\
\hline & $\mathrm{C}^{*}$ & 5.69 & 5.50 & 6.67 & $4.22^{\mathrm{y}}$ & $4.79^{y}$ & $7.43^{\mathrm{x}}$ & $7.37^{\mathrm{x}}$ & 0.051 & $<0.001$ & 1.388 \\
\hline & $\mathrm{H}^{*}$ & 94.16 & 97.22 & 94.63 & 100.31 & 95.00 & 90.92 & 95.11 & 0.764 & 0.3585 & 12.651 \\
\hline \multirow[t]{5}{*}{ Ventral } & $L^{*}$ & 50.94 & 51.33 & 49.63 & $47.99^{z}$ & $49.37^{\mathrm{yz}}$ & $51.29^{x y}$ & $53.90^{\mathrm{x}}$ & 0.159 & $<0.001$ & 2.557 \\
\hline & $a^{*}$ & 0.78 & 1.20 & 0.92 & 0.24 & 1.73 & 1.49 & 0.42 & 0.684 & 0.253 & 1.391 \\
\hline & $b^{*}$ & 6.35 & 7.07 & 6.96 & $4.03^{y}$ & $6.95^{\mathrm{x}}$ & $8.41^{\mathrm{x}}$ & $7.78^{x}$ & 0.268 & $<0.001$ & 1.333 \\
\hline & $\mathrm{C}^{*}$ & 6.60 & 7.42 & 7.29 & $4.27^{\mathrm{y}}$ & $7.35^{\mathrm{x}}$ & $8.76^{x}$ & $8.04^{\mathrm{x}}$ & 0.240 & $<0.001$ & 1.441 \\
\hline & $\mathrm{H}^{*}$ & 83.76 & 83.56 & 87.77 & $89.52^{x}$ & $79.21^{\mathrm{y}}$ & $82.24^{x y}$ & $89.15^{\mathrm{x}}$ & 0.330 & 0.015 & 8.873 \\
\hline WHC, $\%$ & & 84.72 & 85.16 & 84.25 & 86.96 & 83.47 & 84.49 & 83.92 & 0.715 & 0.054 & 3.176 \\
\hline Cooking loss, $\%$ & & 7.90 & 10.22 & 10.02 & $7.92^{x y}$ & $12.55^{\mathrm{x}}$ & $6.01^{\mathrm{y}}$ & $11.05^{\mathrm{xy}}$ & 0.109 & $<0.001$ & 3.355 \\
\hline \multicolumn{12}{|l|}{ Cooked fillet } \\
\hline Shear stress, N & & 13.46 & 14.75 & 11.73 & $9.89^{\mathrm{y}}$ & $12.66^{\mathrm{xy}}$ & $13.67^{x y}$ & $17.05^{\mathrm{x}}$ & 0.363 & 0.045 & 5.946 \\
\hline \multicolumn{12}{|l|}{ Colour } \\
\hline \multirow[t]{5}{*}{ Dorsal } & $\mathrm{L}^{*}$ & 77.48 & 76.08 & 74.66 & 0.75 & 78.63 & 74.04 & 76.34 & 0.226 & 0.105 & 4.542 \\
\hline & $a^{*}$ & -0.25 & -0.33 & -0.25 & $-0.88^{\mathrm{y}}$ & $-0.01^{x}$ & $-0.15^{x y}$ & $-0.06^{\mathrm{x}}$ & 0.920 & 0.010 & 0.678 \\
\hline & $\mathrm{b}^{*}$ & 11.28 & 11.05 & 12.29 & 11.93 & 12.26 & 10.54 & 11.41 & 0.187 & 0.188 & 2.000 \\
\hline & $\mathrm{C}^{*}$ & 11.32 & 11.09 & 12.36 & 12.03 & 12.29 & 10.59 & 11.44 & 0.175 & 0.180 & 1.988 \\
\hline & $\mathrm{H}^{*}$ & 92.11 & 92.72 & 91.97 & $95.56^{\mathrm{x}}$ & $90.74^{\mathrm{y}}$ & $91.93^{x y}$ & $90.84^{\mathrm{y}}$ & 0.836 & 0.010 & 3.759 \\
\hline \multirow[t]{5}{*}{ Ventral } & $\mathrm{L}^{*}$ & 74.07 & 72.56 & 70.28 & $70.67^{x y}$ & $76.40^{\mathrm{x}}$ & $66.97^{y}$ & $75.18^{x}$ & 0.141 & $<0.001$ & 5.306 \\
\hline & $a^{*}$ & 0.36 & 0.63 & 0.74 & $0.91^{x y}$ & $1.02^{\mathrm{x}}$ & $0.40^{\mathrm{xy}}$ & $-0.02^{\mathrm{y}}$ & 0.475 & 0.028 & 0.896 \\
\hline & $\mathrm{b}^{*}$ & 12.44 & 12.22 & 12.9 & 13.02 & 13.68 & 11.24 & 12.13 & 0.714 & 0.083 & 2.370 \\
\hline & $\mathrm{C}^{*}$ & 12.48 & 12.31 & 12.97 & 13.15 & 13.76 & 11.28 & 12.15 & 0.727 & 0.078 & 2.409 \\
\hline & $\mathrm{H}^{*}$ & 88.92 & 88.13 & 87.44 & $87.17^{x y}$ & $86.19^{\mathrm{y}}$ & $88.74^{x y}$ & $90.55^{\mathrm{x}}$ & 0.526 & 0.032 & 3.648 \\
\hline
\end{tabular}

6 RMSE, root mean square error.

$7 \mathrm{x}, \mathrm{y}, \mathrm{z}$ : Different letters indicate significantly different values $(P<0.05)$ within Time $(\mathrm{T})$.

8 The interaction $\mathrm{D} \times \mathrm{T}$ was not significant $(P<0.05)$. 
10 Table 2. Total lipids ( $\mathrm{g} \mathrm{kg}^{-1}$ fillet), total fatty acids $\left(\mathrm{g} \mathrm{kg}^{-1}\right.$ fillet), and fatty acid profile ( $\%$ of

11 total fatty acids) of raw fillets from rainbow trout fed three experimental diets: Control (C)

12 with fish meal as the main protein source, Hi25, and Hi50 with the $25 \%$ and $50 \%$ of fish meal

13 substitution by Hermetia illucens, respectively. Fillets from the three groups were stored 120

14 days at $-10^{\circ} \mathrm{C}$.

\begin{tabular}{|c|c|c|c|c|c|c|c|c|c|c|}
\hline & \multicolumn{3}{|c|}{ Diet (D) } & \multicolumn{4}{|c|}{ Time $(\mathrm{T})$} & \multicolumn{2}{|c|}{$P$-value } & \multirow[t]{2}{*}{ RMSE } \\
\hline & $\mathrm{C}$ & $\mathrm{Hi} 25$ & Hi50 & $\mathrm{T} 1$ & T30 & T90 & T120 & $\mathrm{D}$ & $\mathrm{T}$ & \\
\hline Total lipids & 88.0 & 96.2 & 98.0 & $116.3^{x}$ & $89.9^{y}$ & $86.9^{\mathrm{y}}$ & $83.0^{\mathrm{y}}$ & 0.183 & $<0.001$ & 1.59 \\
\hline Total fatty acids & 70.5 & 76.8 & 78.4 & $92.8^{x}$ & $72.1^{\mathrm{y}}$ & $69.6^{\mathrm{y}}$ & $66.5^{\mathrm{y}}$ & 0.196 & $<0.001$ & 1.27 \\
\hline $\mathrm{C} 12: 0$ & $0.60^{c}$ & $6.33^{b}$ & $12.08^{\mathrm{a}}$ & $5.79^{\mathrm{y}}$ & $6.45^{\mathrm{x}}$ & $6.44^{\mathrm{x}}$ & $6.67^{\mathrm{x}}$ & $<0.001$ & 0.004 & 0.569 \\
\hline $\mathrm{C} 14: 0$ & $3.23^{\mathrm{c}}$ & $4.29^{\mathrm{b}}$ & $5.35^{\mathrm{a}}$ & $4.14^{\mathrm{y}}$ & $4.32^{\mathrm{x}}$ & $4.30^{\mathrm{x}}$ & $4.39^{\mathrm{x}}$ & $<0.001$ & 0.004 & 0.159 \\
\hline C16:0 & 15.23 & 15.65 & 15.61 & 15.14 & 15.63 & 15.69 & 15.52 & 0.085 & 0.100 & 0.574 \\
\hline C18:0 & 3.62 & 3.72 & 3.64 & 3.68 & 3.69 & 3.63 & 3.64 & 0.242 & 0.739 & 0.174 \\
\hline SFA & $23.49^{\mathrm{c}}$ & $30.71^{\mathrm{b}}$ & $37.30^{\mathrm{a}}$ & $29.50^{y}$ & $30.83^{x}$ & $30.75^{\mathrm{x}}$ & $30.93^{\mathrm{x}}$ & $<0.001$ & 0.008 & 1.085 \\
\hline $\mathrm{C} 16: 1 \omega 7$ & 5.43 & 5.56 & 5.52 & 5.29 & 5.61 & 5.55 & 5.57 & 0.585 & 0.170 & 0.372 \\
\hline $\mathrm{C} 18: 1 \omega 7$ & $2.81^{\mathrm{a}}$ & $2.53^{\mathrm{b}}$ & $2.30^{\mathrm{c}}$ & 2.55 & 2.53 & 2.57 & 2.54 & $<0.001$ & 0.372 & 0.068 \\
\hline 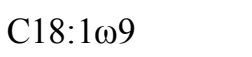 & $22.63^{\mathrm{a}}$ & $22.08^{\mathrm{ab}}$ & $21.56^{\mathrm{b}}$ & 22.16 & 22.14 & 22.2 & 21.87 & 0.001 & 0.650 & 0.703 \\
\hline $\mathrm{C} 20: 1 \omega 9$ & $2.33^{\mathrm{a}}$ & $2.26^{\mathrm{a}}$ & $1.90^{\mathrm{b}}$ & 2.22 & 2.20 & 2.19 & 2.05 & 0.008 & 0.694 & 0.391 \\
\hline $\mathrm{C} 22: 1 \omega 11$ & $1.34^{\mathrm{a}}$ & $1.07^{\mathrm{b}}$ & $0.73^{\mathrm{c}}$ & 1.07 & 1.04 & 1.01 & 1.06 & $<0.001$ & 0.604 & 0.113 \\
\hline MUFA & $36.17^{\mathrm{a}}$ & $34.91^{\mathrm{b}}$ & $33.32^{\mathrm{c}}$ & 34.67 & 34.91 & 34.93 & 34.69 & $<0.001$ & 0.863 & 0.955 \\
\hline $\mathrm{C} 18: 3 \omega 3$ & $1.86^{\mathrm{a}}$ & $1.61^{\mathrm{b}}$ & $1.53^{\mathrm{b}}$ & 1.73 & 1.65 & 1.66 & 1.63 & $<0.001$ & 0.402 & 0.146 \\
\hline $\mathrm{C} 20: 5 \omega 3$ & $4.12^{\mathrm{a}}$ & $3.16^{\mathrm{b}}$ & $2.18^{\mathrm{c}}$ & 3.27 & 3.14 & 3.07 & 3.22 & $<0.001$ & 0.070 & 0.183 \\
\hline $\mathrm{C} 22: 5 \omega 3$ & $2.40^{\mathrm{a}}$ & $1.74^{\mathrm{b}}$ & $1.19^{\mathrm{c}}$ & $1.91^{\mathrm{x}}$ & $1.70^{\mathrm{y}}$ & $1.75^{\mathrm{y}}$ & $1.75^{\mathrm{y}}$ & $<0.001$ & 0.003 & 0.137 \\
\hline $\mathrm{C} 22: 6 \omega 3$ & $18.58^{\mathrm{a}}$ & $15.96^{\mathrm{b}}$ & $12.72^{\mathrm{c}}$ & 16.15 & 15.59 & 15.6 & 15.66 & $<0.001$ & 0.219 & 0.749 \\
\hline PUFA $\omega 3$ & $29.12^{\mathrm{a}}$ & $24.13^{\mathrm{b}}$ & $18.87^{\mathrm{c}}$ & 24.7 & 23.71 & 23.78 & 23.98 & $<0.001$ & 0.307 & 0.966 \\
\hline $\mathrm{C} 18: 2 \omega 6$ & 7.73 & 7.24 & 7.83 & 8.00 & 7.50 & 7.54 & 7.36 & 0.076 & 0.210 & 0.760 \\
\hline PUFAw6 & $10.11^{\mathrm{a}}$ & $9.31^{\mathrm{b}}$ & $9.80^{\mathrm{ab}}$ & 10.20 & 9.64 & 9.66 & 9.47 & 0.040 & 0.201 & 0.864 \\
\hline PUFA & $40.13^{\mathrm{a}}$ & $34.58^{\mathrm{b}}$ & $29.52^{c}$ & 35.83 & 34.26 & 34.51 & 34.38 & $<0.001$ & 0.127 & 1.778 \\
\hline
\end{tabular}

15

16

17

18

19

20

21

22

23

RMSE, root mean square error.

a, b, c: Different letters indicate significantly different values $(P<0.05)$ within Diet (D).

$\mathrm{x}, \mathrm{y}, \mathrm{z}$ : Different letters indicate significantly different values $(P<0.05)$ within Time $(\mathrm{T})$.

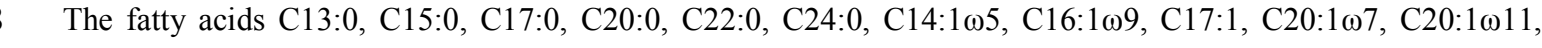
$\mathrm{C} 22: 1 \omega 9, \mathrm{C} 22: 1 \omega 7, \mathrm{C} 18: 4 \omega 3, \mathrm{C} 20: 3 \omega 3, \mathrm{C} 20: 4 \omega 3, \mathrm{C} 21: 5 \omega 3, \mathrm{C} 18: 3 \omega 6, \mathrm{C} 20: 2 \omega 6, \mathrm{C} 20: 3 \omega 6, \mathrm{C} 20: 4 \omega 6, \mathrm{C} 22: 2 \omega 6$, $\mathrm{C} 22: 4 \omega 6, \mathrm{C} 22: 5 \omega 6$ were detected but not listed in the table because below 1.5\%. All the mentioned fatty acids have been utilized for calculating the sums of the lipid fractions.

The interaction $\mathrm{D} \times \mathrm{T}$ was not significant $(P<0.05)$. 
24 Table 3. Total lipids ( $\mathrm{g} \mathrm{kg}^{-1}$ fillet), total fatty acids ( $\mathrm{g} \mathrm{kg}^{-1}$ fillet), and fatty acid profile (\% of

25 total fatty acids) of cooked fillets from rainbow trout fed three experimental diets: Control (C)

26 with fish meal as the main protein source, Hi25, and Hi50 with the $25 \%$ and $50 \%$ of fish meal

27 substitution by Hermetia illucens, respectively. Fillets from the three groups were stored 120

28 days at $-10^{\circ} \mathrm{C}$.

\begin{tabular}{|c|c|c|c|c|c|c|c|c|c|c|}
\hline & \multicolumn{3}{|c|}{ Diet (D) } & \multicolumn{4}{|c|}{ Time $(\mathrm{T})$} & \multicolumn{2}{|c|}{$P$-value } & \multirow{2}{*}{ RMSE } \\
\hline & $\mathrm{C}$ & Hi25 & Hi50 & $\mathrm{T} 1$ & T30 & T90 & $\mathrm{T} 120$ & $\bar{D}$ & $\mathrm{~T}$ & \\
\hline Total lipids & 78.4 & 81.3 & 77.3 & 84.3 & 74.0 & 80.4 & 77.2 & 0.766 & 0.449 & 1.603 \\
\hline Total fatty acids & 6.27 & 6.51 & 6.17 & 6.75 & 5.92 & 6.42 & 6.17 & 0.755 & 0.442 & 1.282 \\
\hline $\mathrm{C} 12: 0$ & $1.17^{\mathrm{c}}$ & $6.00^{\mathrm{b}}$ & $11.68^{\mathrm{a}}$ & $5.64^{\mathrm{y}}$ & $6.95^{\mathrm{x}}$ & $6.07^{x y}$ & $6.48^{x y}$ & $<0.001$ & 0.038 & 1.103 \\
\hline $\mathrm{C} 14: 0$ & $3.23^{\mathrm{c}}$ & $4.18^{b}$ & $5.08^{\mathrm{a}}$ & $3.77^{\mathrm{y}}$ & $4.32^{\mathrm{x}}$ & $4.23^{\mathrm{x}}$ & $4.35^{\mathrm{x}}$ & 0.019 & $<0.001$ & 0.478 \\
\hline $\mathrm{C} 16: 0$ & $15.22^{\mathrm{b}}$ & $15.67^{\mathrm{a}}$ & $15.73^{\mathrm{a}}$ & 15.17 & 15.63 & 15.68 & 15.67 & 0.010 & 0.143 & 0.487 \\
\hline C18:0 & 3.61 & 3.74 & 3.67 & 3.68 & 3.71 & 3.63 & 3.68 & 0.100 & 0.688 & 0.161 \\
\hline SFA & $24.03^{c}$ & $30.30^{\mathrm{b}}$ & $36.66^{\mathrm{a}}$ & $28.82^{y}$ & $31.33^{\mathrm{x}}$ & $30.30^{\mathrm{x}}$ & $30.89^{x}$ & $<0.001$ & 0.003 & 1.597 \\
\hline $\mathrm{C} 16: 1 \omega 7$ & 5.20 & 5.39 & 5.44 & 5.06 & 5.39 & 5.48 & 5.42 & 0.173 & 0.146 & 0.378 \\
\hline $\mathrm{C} 18: 1 \omega 7$ & $2.75^{\mathrm{a}}$ & $2.49^{\mathrm{b}}$ & $2.27^{\mathrm{c}}$ & 2.49 & 2.45 & 2.54 & 2.53 & $<0.001$ & 0.353 & 0.068 \\
\hline 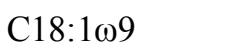 & $21.86^{\mathrm{a}}$ & $21.61^{\mathrm{ab}}$ & $21.14^{\mathrm{b}}$ & 21.43 & 21.49 & 21.83 & 21.39 & 0.016 & 0.388 & 0.677 \\
\hline 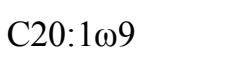 & $2.43^{\mathrm{a}}$ & $2.22^{\mathrm{a}}$ & $1.65^{\mathrm{b}}$ & 2.17 & 2.15 & 2.18 & 1.91 & $<0.001$ & 0.230 & 0.364 \\
\hline $\mathrm{C} 22: 1 \omega 11$ & $1.31^{\mathrm{a}}$ & $1.07^{\mathrm{b}}$ & $0.69^{c}$ & 1.04 & 1.00 & 1.00 & 1.06 & $<0.001$ & 0.746 & 0.147 \\
\hline MUFA & $35.00^{\mathrm{a}}$ & $34.17^{\mathrm{a}}$ & $32.45^{\mathrm{b}}$ & 33.54 & 33.86 & 34.43 & 33.67 & $<0.001$ & 0.240 & 1.123 \\
\hline $\mathrm{C} 18: 3 \omega 3$ & $1.81^{\mathrm{a}}$ & $1.57^{\mathrm{b}}$ & $1.50^{\mathrm{b}}$ & 1.69 & 1.60 & 1.62 & 1.59 & $<0.001$ & 0.307 & 0.136 \\
\hline $\mathrm{C} 20: 5 \omega 3$ & $4.21^{\mathrm{a}}$ & $3.23^{\mathrm{b}}$ & $2.29^{c}$ & 3.37 & 3.16 & 3.14 & 3.31 & $<0.001$ & 0.213 & 0.189 \\
\hline $\mathrm{C} 22: 5 \omega 3$ & $2.39^{\mathrm{a}}$ & $1.80^{\mathrm{b}}$ & $1.23^{\mathrm{c}}$ & $1.98^{\mathrm{x}}$ & $1.70^{\mathrm{y}}$ & $1.80^{\mathrm{y}}$ & $1.76^{\mathrm{y}}$ & $<0.001$ & 0.001 & 0.159 \\
\hline $\mathrm{C} 22: 6 \omega 3$ & $19.58^{\mathrm{a}}$ & $17.18^{\mathrm{b}}$ & $14.19^{c}$ & $18.05^{\mathrm{x}}$ & $16.47^{\mathrm{y}}$ & $16.56^{\mathrm{y}}$ & $16.86^{\mathrm{y}}$ & $<0.001$ & 0.005 & 1.118 \\
\hline PUFAw3 & $30.03^{\mathrm{a}}$ & $25.43^{\mathrm{b}}$ & $20.43^{c}$ & $26.66^{x}$ & $24.55^{\mathrm{y}}$ & $24.80^{\mathrm{y}}$ & $25.19^{y}$ & $<0.001$ & 0.002 & 1.349 \\
\hline $\mathrm{C} 18: 2 \omega 6$ & 7.50 & 7.03 & 7.63 & 7.76 & 7.25 & 7.38 & 7.16 & 0.052 & 0.188 & 0.696 \\
\hline 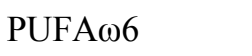 & 9.90 & 9.19 & 9.74 & 10.12 & 9.39 & 9.59 & 9.35 & 0.053 & 0.098 & 0.820 \\
\hline PUFA & $40.97^{\mathrm{a}}$ & $35.53^{\mathrm{b}}$ & $30.88^{c}$ & $37.64^{x}$ & $34.81^{\mathrm{y}}$ & $35.27^{\mathrm{y}}$ & $35.44^{\mathrm{y}}$ & $<0.001$ & 0.010 & 2.084 \\
\hline$\omega 3 / \omega 6$ & $3.04^{\mathrm{a}}$ & $2.78^{\mathrm{b}}$ & $2.10^{\mathrm{c}}$ & 2.66 & 2.64 & 2.58 & 2.68 & $<0.001$ & 0.393 & 0.146 \\
\hline PUFA/SFA & $1.72^{\mathrm{a}}$ & $1.18^{\mathrm{b}}$ & $0.85^{\mathrm{c}}$ & $1.37^{\mathrm{x}}$ & $1.16^{\mathrm{y}}$ & $1.23^{\mathrm{y}}$ & $1.23^{\mathrm{y}}$ & $<0.001$ & 0.010 & 0.142 \\
\hline AI & $0.39^{c}$ & $0.56^{\mathrm{b}}$ & $0.76^{\mathrm{a}}$ & $0.51^{y}$ & $0.60^{x}$ & $0.57^{x}$ & $0.60^{\mathrm{x}}$ & $<0.001$ & 0.003 & 0.061 \\
\hline $\mathrm{TI}$ & $0.19^{c}$ & $0.23^{\mathrm{b}}$ & $0.29^{\mathrm{a}}$ & $0.22^{\mathrm{y}}$ & $0.25^{\mathrm{x}}$ & $0.24^{\mathrm{x}}$ & $0.24^{\mathrm{x}}$ & $<0.001$ & 0.002 & 0.020 \\
\hline $\mathrm{HH}$ & $3.16^{\mathrm{a}}$ & $2.69^{b}$ & $2.38^{\mathrm{c}}$ & $2.96^{\mathrm{x}}$ & $2.65^{\mathrm{y}}$ & $2.69^{\mathrm{y}}$ & $2.66^{\mathrm{y}}$ & $<0.001$ & 0.004 & 0.222 \\
\hline \multicolumn{11}{|c|}{ RMSE, root mean square error. } \\
\hline \multicolumn{11}{|c|}{ a, b, c: Different letters indicate significantly different values $(P<0.05)$ within Diet (D). } \\
\hline \multicolumn{11}{|c|}{$\mathrm{x}, \mathrm{y}, \mathrm{z}$ : Different letters indicate significantly different values $(P<0.05)$ within Time $(\mathrm{T})$. } \\
\hline & & & & & & 1410 & $C_{1}$ & $\mathrm{C} 17$. & 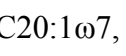 & \\
\hline
\end{tabular}


$34 \mathrm{C} 22: 4 \omega 6, \mathrm{C} 22: 5 \omega 6$ were detected but not listed in the table because below $1.5 \%$. All the mentioned fatty acids 35 have been utilized for calculating the sums of the lipid fractions.

36 The interaction $\mathrm{D} \times \mathrm{T}$ was not significant $(P<0.05)$.

10

11

12

13

14

15

16

17

18

19

20

21

22

23

24

25

26

27

28

29

30

31

32

33

34

35

36

37

38

39

40

41

42

43

44

45

46

47

48

49

50

51

52

53

54

55

56

57

58

59

60 


\section{Captions of Figures}

2

3 Figure 1. TBARS and CD contents at $\mathrm{T} 1$ and $\mathrm{T} 120$ (mg MDA-eq $\mathrm{kg}^{-1} ; \mathrm{mmol} \mathrm{Hp} \mathrm{kg}{ }^{-1}$ fillets)

4 of raw fillets from rainbow trout fed three experimental diets: Control (C) with fish meal as

5 the main protein source, Hi25, and Hi50 with the $25 \%$ and $50 \%$ of fish meal substitution by

6 Hermetia illucens, respectively.

7

8

$9 \quad$ Figure 2. Biplot of principal component (PC) analysis of raw fillets.

12 Figure 3. Biplot of principal component (PC) analysis of cooked fillets. 


\section{Figure 1.}
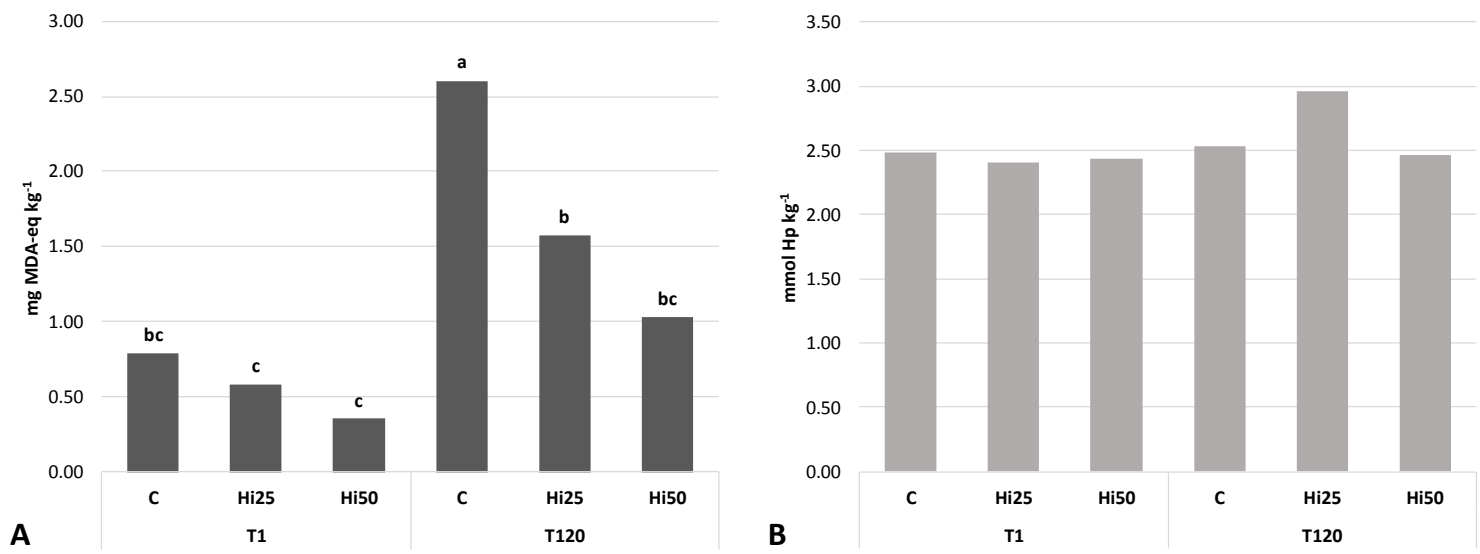

15 A. TBARS - thiobarbituric acid-reactive substances; B. CD - conjugated dienes.

a, b, c: Different letters indicate significantly different values $(P<0.05)$.

17 


\section{$18 \quad$ Figure 2.}

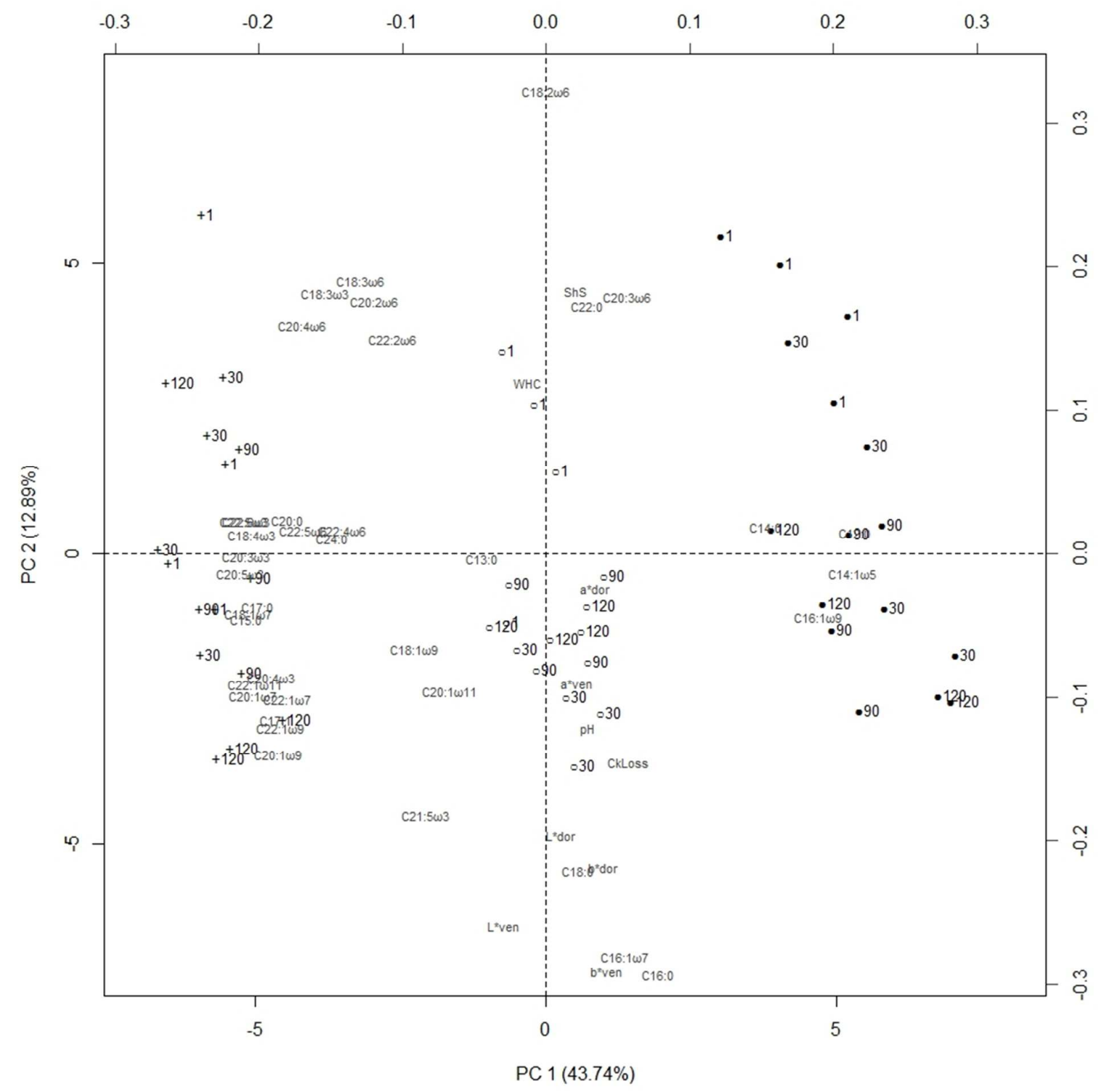

19

$20+$ : Control (C) diet; $\bigcirc: 25 \%$ of fish meal substitution by Hermetia illucens meal (Hi25); $\bullet: 50 \%$ of fish

21 meal substitution by Hermetia illucens meal (Hi50). 
22 Figure 3.

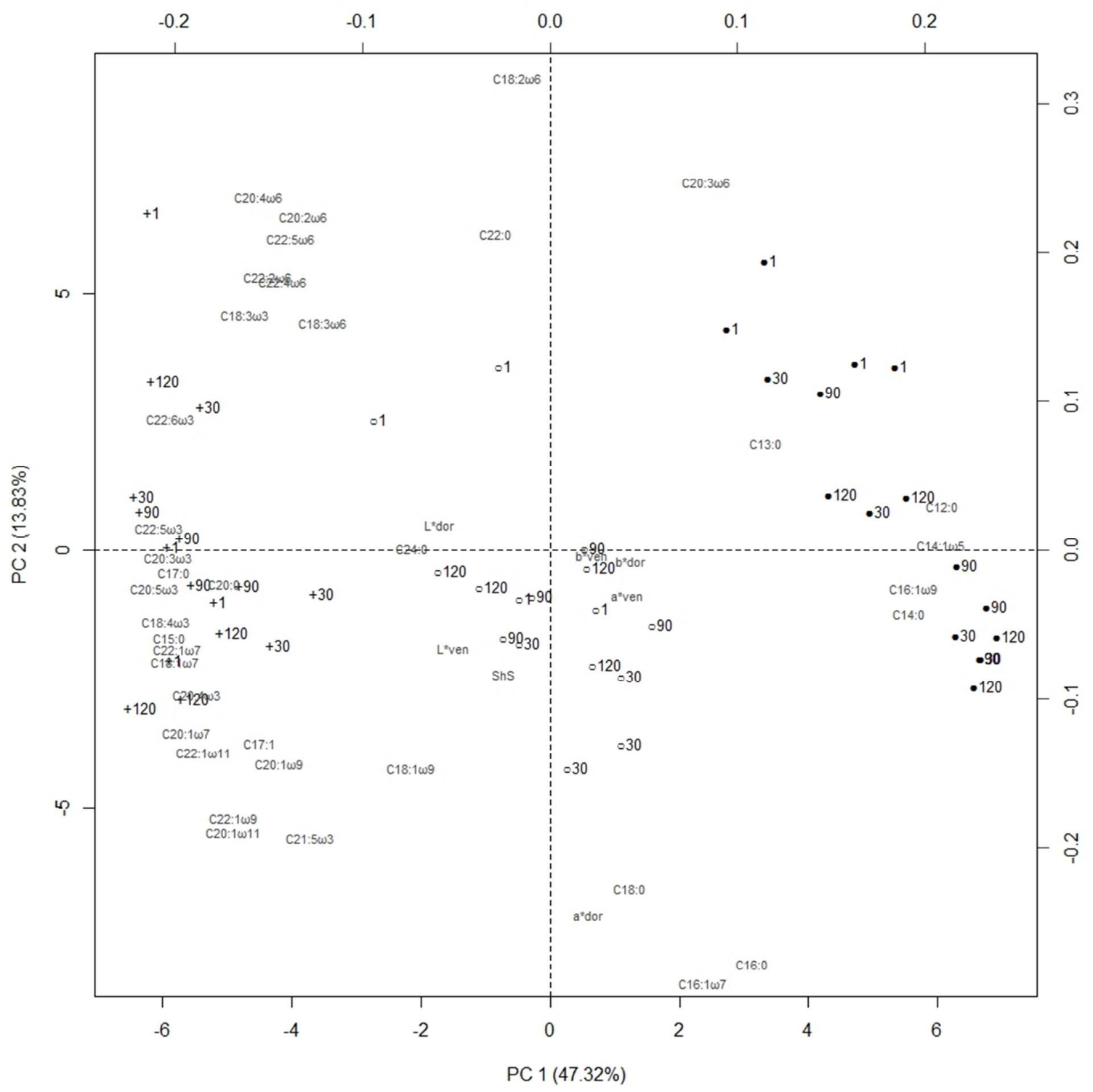

23

$24+$ : Control (C) diet; ○: 25\% of fish meal substitution by Hermetia illucens meal (Hi25); •: 50\% of fish

25 meal substitution by Hermetia illucens meal (Hi50). 